\title{
Quantifying Aerosol Delivery in Simulated Spontaneously Breathing Patients With Tracheostomy Using Different Humidification Systems With or Without Exhaled Humidity
}

\author{
Arzu Ari PhD RRT PT CPFT FAARC, Robert Harwood MSA RRT FAARC, \\ Meryl Sheard MSc RRT, Maher Mubarak Alquaimi MSc RRT, Bshayer Alhamad MSc, and \\ James B Fink PhD RRT FAARC
}

\begin{abstract}
BACKGROUND: Aerosol and humidification therapy are used in long-term airway management of critically ill patients with a tracheostomy. The purpose of this study was to determine delivery efficiency of jet and mesh nebulizers combined with different humidification systems in a model of a spontaneously breathing tracheotomized adult with or without exhaled heated humidity. METHODS: An in vitro model was constructed to simulate a spontaneously breathing adult (tidal volume, $400 \mathrm{~mL}$; breathing frequency, 20 breaths/min; inspiratory-expiratory ratio, 1:2) with a tracheostomy using a teaching manikin attached to a test lung through a collecting filter (Vital Signs Respirgard II). Exhaled heat and humidity were simulated using a cascade humidifier set to deliver $37^{\circ} \mathrm{C}$ and $>95 \%$ relative humidity. Albuterol sulfate $(2.5 \mathrm{mg} / 3 \mathrm{~mL})$ was administered with a jet nebulizer (AirLife Misty Max) operated at $10 \mathrm{~L} / \mathrm{min}$ and a mesh nebulizer (Aeroneb Solo) using a heated pass-over humidifier, unheated large volume humidifier both at $40 \mathrm{~L} / \mathrm{min}$ output and heatand-moisture exchanger. Inhaled drug eluted from the filter was analyzed via spectrophotometry $(276 \mathrm{~nm})$. RESULTS: Delivery efficiency of the jet nebulizer was less than that of the mesh nebulizer under all conditions $(P<\mathbf{. 0 5})$. Aerosol delivery with each nebulizer was greatest on room air and lowest when heated humidifiers with higher flows were used. Exhaled humidity decreased drug delivery up to $44 \%$. CONCLUSIONS: The jet nebulizer was less efficient than the mesh nebulizer in all conditions tested in this study. Aerosol deposition with each nebulizer was lowest with the heated humidifier with high flow. Exhaled humidity reduced inhaled dose of drug compared with a standard model with nonheated/nonhumidified exhalation. Further clinical research is warranted to understand the impact of exhaled humidity on aerosol drug delivery in spontaneously breathing patients with tracheostomy using different types of humidifiers. Key words: aerosols; nebulizers; humidification; drug delivery; and tracheostomy. [Respir Care 2016;61(5):600-606. (c) 2016 Daedalus Enterprises]
\end{abstract}

\section{Introduction}

Aerosol and humidification therapy are commonly used as part of long-term airway management in critically ill

\footnotetext{
Dr Ari, Mr Harwood, Ms Sheard, and Ms Alhamad are affiliated with the Department of Respiratory Therapy, Georgia State University, Atlanta, Georgia. Mr Alquaimi is affiliated with the University of Dammam, Dammam, Saudi Arabia. Dr Fink is affiliated with James B Fink, LLC, San Mateo, California, and the Department of Respiratory Therapy, Georgia State University, Atlanta, Georgia.
}

This study was funded by the American Respiratory Care Foundation. Dr patients with a tracheostomy. Since the upper airway is bypassed, providing heat and humidity is essential in this

\footnotetext{
Ari has disclosed a relationship with Aerogen Ltd. Dr Fink has disclosed relationships with Aerogen, Bayer, Boerhinger Ingleheim, Dance Biopharm, Novartis, ONY, Parion, Aridis, and the World Health Organization. No company had input into the study design or execution. The other authors have disclosed no conflicts of interest.
}

Correspondence: Arzu Ari PhD RRT PT CPFT FAARC, Department of Respiratory Therapy, Georgia State University, P.O. Box 4019, Georgia 30302-4019. E-mail: arzuari@ hotmail.com.

DOI: $10.4187 /$ respcare.04127 
patient population. Three types of humidification devices are commonly used in patients with a tracheostomy: heated humidifiers, unheated humidifiers and heat-and-moisture exchangers (HME). These humidification devices are usually combined with nebulizers to deliver aerosolized medications, such as bronchodilators, that are used for the treatment of patients with artificial airways.

Inhaled aerosols may be delivered by jet nebulizers or mesh nebulizers in spontaneously breathing patients with a tracheostomy. Whereas jet nebulizers are widely used in critically ill patients, use of mesh nebulizers in patients with a tracheostomy has been more recently introduced, and its efficiency in such patient populations is unknown. Although evidence indicates that variables associated with artificial airways affect aerosol deposition during mechanical ventilation, ${ }^{1-9}$ research has focused almost exclusively on aerosol delivery through an endotracheal tube. Therefore, research about the delivery of inhaled medications administered with different aerosol delivery devices in spontaneously breathing patients with a tracheostomy is limited.

Previous research reported a reduction in aerosol deposition with heated humidified circuits compared with unheated dry ventilator circuits. None of these models have simulated exhaled heat and humidity, which may affect aerosol deposition. To better simulate patient aerosol interactions, it is important to understand the impact of exhaled, heated, and humidified gas through artificial airways on aerosol deposition and relative humidity in critically ill patients with a tracheostomy. Quantifying and comparing efficiencies of nebulizers in patients with a tracheostomy is essential in providing guidance to clinicians. Using the most efficient aerosol device leads to improved pulmonary deposition of drugs and possibly greater clinical benefit in spontaneously breathing patients with a tracheostomy.

The purpose of this study was to quantify the delivery efficiency of aerosol devices with relative humidity in a lung model of a spontaneously ventilated adult with a tracheostomy in which exhaled humidity is simulated. The hypothesis of this study is that delivery efficiency and relative humidity are different depending on the type of nebulizer and humidifier used in patients with a tracheostomy. The research questions of this study are as follows: (1) What is the difference in delivery efficiency between jet nebulizers and mesh nebulizers used during the treatment of patients with a tracheostomy? (2) How does aerosol delivery efficiency differ when a jet nebulizer and vibrating mesh nebulizer are combined with different types of humidifiers? (3) What is the effect of exhaled humidity on the amount of drug deposition using a jet nebulizer and mesh nebulizer with each type of humidifier in simulated spontaneously breathing adults with a tracheostomy?

\section{QUICK LOOK}

\section{Current knowledge}

Aerosol and humidification therapy are commonly used as part of long-term airway management in critically ill patients with a tracheostomy. Inhaled aerosols may be delivered by jet nebulizers or mesh nebulizers in spontaneously breathing patients with a tracheostomy. Previous research reported a reduction in aerosol deposition with heated humidified ventilator circuits compared with unheated dry ventilator circuits.

\section{What this paper contributes to our knowledge}

This paper demonstrates the effects of commonly used nebulizer/humidification combinations and exhaled air on aerosol deposition in a simulated lung model of tracheostomy. There were substantial differences in drug delivered distal to the trachea between the types of nebulizer, the 4 conditions of humidification, and the 2 models used. Aerosol drug delivery with each nebulizer was lowest with the heated humidifier and highest with the HME. Whereas the jet nebulizer was less efficient than the mesh nebulizer in all conditions tested in this study, exhaled humidity caused a decrease in aerosol deposition compared with nonheated/humidified exhalation.

\section{Methods}

\section{Study Variables}

The independent variables of this study are nebulizers and humidity devices. Both a jet nebulizer (AirLife MistyMax 10, CareFusion, San Diego, California) and vibrating mesh nebulizer (Aeroneb Solo, Aerogen Ltd, Galway, Ireland) were tested in this study, with 3 types of humidification systems, including a heated humidifier (Fisher Paykel Healthcare, Irvine, California) and an unheated humidifier (Moore Medical, Farmington, Connecticut), both operated at a flow of $40 \mathrm{~L} / \mathrm{min}$ and an HME (Trach-Vent + , Teleflex Medical, Athlone, Ireland) with no additional external flow. The outcome variable of this study is aerosol deposition distal to the tracheostomy tube.

\section{Research Design}

Figure 1 represents the scheme of the research design of this study with each type of aerosol and humidity device tested in this study. Each nebulizer was tested with a heated humidifier, unheated humidifier, and HME with or without active exhaled humidity. In addition, aerosol delivery 


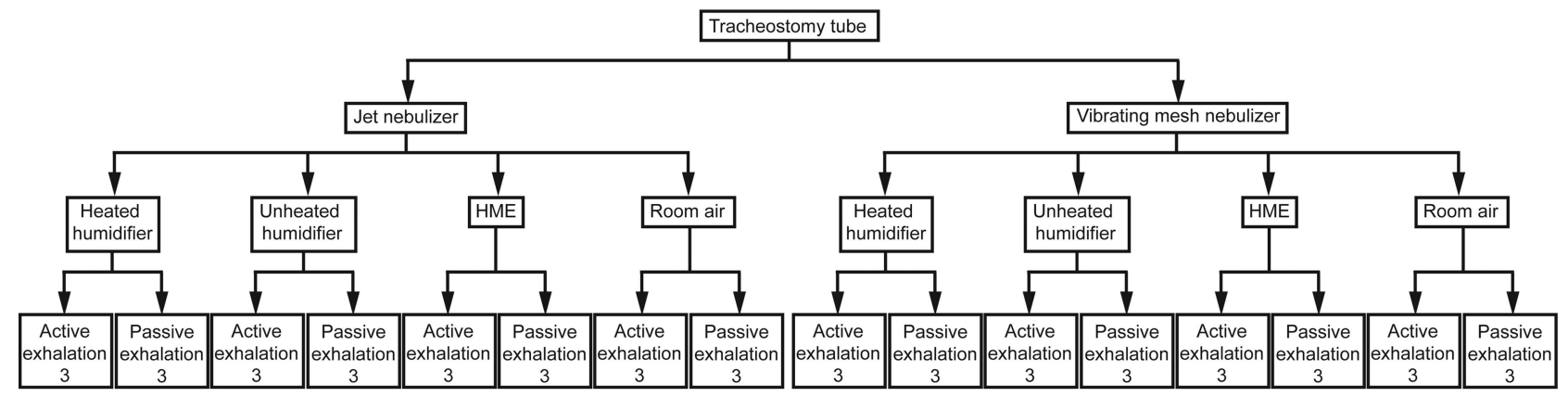

Fig. 1. Flow chart.

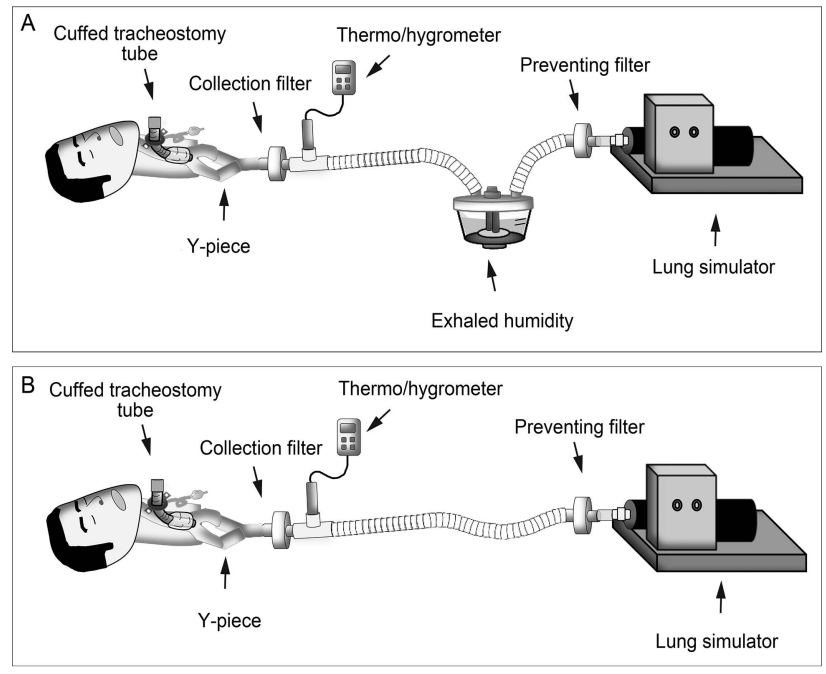

Fig. 2. The lung models used in this study with $(A)$ and without $(B)$ exhaled humidity.

with a jet nebulizer and a mesh nebulizer was tested on room air, which served as the control group of this study. Each condition was repeated in triplicate $(n=3)$.

\section{Lung Model}

An in vitro lung model was constructed to simulate spontaneously breathing adults with a tracheostomy. An anatomical teaching manikin was intubated with a standard tracheostomy tube of 8-mm inner diameter. Each main bronchus of the manikin was connected to a Y-adapter, which was attached through a collecting filter (Vital Signs Respirgard II, CareFusion, San Diego, California) to a breathing simulator (Harvard Apparatus, Holliston, Massachusetts). Heated and humidified gas exhaled through the tracheostomy tube was simulated using a cascade humidifier set to deliver $37^{\circ} \mathrm{C}$ and $100 \%$ relative humidity as verified via a digital hygrometer/thermometer (model 485, Dwyer, Michigan City, Indiana). A breathing simulator was set to adult breathing parameters, including tidal volume of $400 \mathrm{~mL}$, frequency of $20 / \mathrm{min}$, and inspiratory- expiratory ratio of 1:2 with a sinusoidal pattern. Figure 2 shows the lung model of this study with (A) and without (B) exhaled humidity, whereas Figure 3 illustrates the experimental setup used: unheated humidifier (A), heated humidifier (B), HME (C) and room air (D).

\section{Data Collection}

As shown in Figure 2, albuterol sulfate $(2.5 \mathrm{mg} / 3 \mathrm{~mL})$ was administered through jet nebulizer and vibrating mesh nebulizer using 3 different types of humidification systems: an unheated humidifier, a heated humidifier, and an HME. The jet nebulizer was run continuously using $8 \mathrm{~L} / \mathrm{min}$ of flow until sputter, whereas the vibrating mesh nebulizer was used until the end of nebulization. Drug was collected on a filter distal to the bronchi of the model. After each run was completed, the filter was detached and eluted with 0.1 $\mathrm{N} \mathrm{HCl}$, and the albuterol was analyzed via spectrophotometry (Beckman Instruments, Fullerton, California) at a wavelength of $276 \mathrm{~nm}$. Using a thermo/hygrometer attached between the collecting filter and the cascade humidifier, relative humidity was measured with each humidifier before and after aerosol therapy administered with each nebulizer. The relative humidity measured in the model distal to the tracheostomy tube was consistently between 95 and 99\% during all experiments. With active exhaled humidity, temperature remained consistently between 35 and $37^{\circ} \mathrm{C}$, whereas the temperature with the non-humidified model was $28-30^{\circ} \mathrm{C}$ with the heated humidifier and $20-25^{\circ} \mathrm{C}$ with the unheated humidifier, HME, and room air measurements.

\section{Data Analysis}

Drug eluted from the filter was analyzed to quantify the inhaled mass of albuterol and expressed as a mean \pm SD percentage of the nominal dose used with each aerosol generator. Inhaled dose percentages delivered by each aerosol device using each humidification system were compared with the Kruskal-Wallis analysis of variance. Differences between humidification systems were determined 

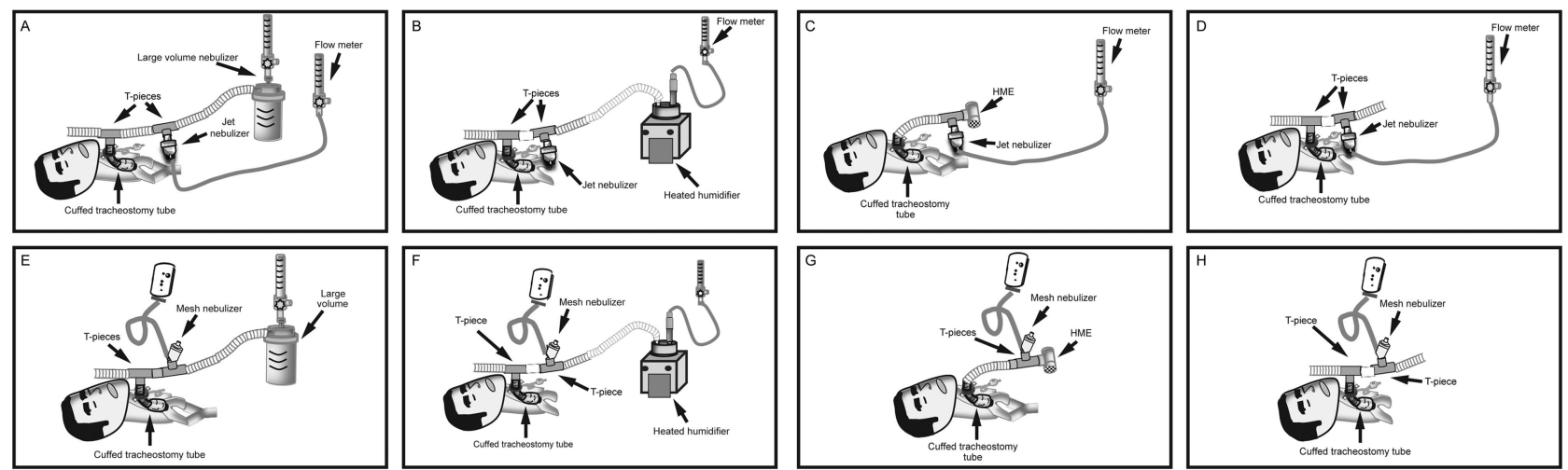

Fig. 3. A-D: Experimental setup with jet nebulizer using an unheated $(A)$ and heated humidifier (B), heat-and-moisture exchanger (HME) (C), and room air (D). E-H: Experimental setup with the mesh nebulizer using an unheated $(E)$ and heated humidifier $(F)$, HME (G), and room air $(H)$.

Table 1. Comparison of the Percentage of the Nominal Dose Delivered Distal to the Trachea With Heated Humidity and Unheated Humidity, Both at $40 \mathrm{~L} / \mathrm{min}$, and Active and Passive Heated Exhalation

\begin{tabular}{|c|c|c|c|c|c|c|}
\hline & \multicolumn{3}{|c|}{ Jet Nebulizer } & \multicolumn{3}{|c|}{ Mesh Nebulizer } \\
\hline & Active Exhalation (\%) & Passive Exhalation (\%) & $P$ & Active Exhalation (\%) & Passive Exhalation (\%) & $P$ \\
\hline $\mathrm{HH}$ & $1.40 \pm 0.22$ & $2.49 \pm 0.13$ & .043 & $3.05 \pm 0.27$ & $3.10 \pm 0.42$ & .89 \\
\hline $\mathrm{UH}$ & $3.09 \pm 0.59$ & $3.70 \pm 0.57$ & .23 & $4.61 \pm 0.35$ & $4.76 \pm 0.44$ & .69 \\
\hline$P$ & .009 & .009 & & .009 & .009 & \\
\hline \multicolumn{7}{|c|}{$\begin{array}{l}\text { Data are mean } \pm \text { SD. } \\
\mathrm{HH}=\text { heated humidity } \\
\mathrm{UH}=\text { unheated humidity }\end{array}$} \\
\hline
\end{tabular}

Table 2. Comparison of the Percentage of the Nominal Dose Delivered Distal to the Trachea With a Heat-and-Moisture Exchanger and Room Air With Active and Passive Heated Exhalation With No Added Flow

\begin{tabular}{|c|c|c|c|c|c|c|}
\hline & \multicolumn{3}{|c|}{ Jet Nebulizer } & \multicolumn{3}{|c|}{ Mesh Nebulizer } \\
\hline & Active Exhalation (\%) & Passive Exhalation (\%) & $P$ & Active Exhalation (\%) & Passive Exhalation (\%) & $P$ \\
\hline HME & $4.58 \pm 0.9$ & $5.98 \pm 0.84$ & .08 & $14.60 \pm 0.88$ & $17.0 \pm 0.45$ & .043 \\
\hline Room air & $6.61 \pm 0.43$ & $6.59 \pm 0.64$ & .89 & $15.78 \pm 2.05$ & $17.67 \pm 1.24$ & .14 \\
\hline$P$ & .009 & .47 & & .30 & .35 & \\
\hline \multicolumn{7}{|c|}{$\begin{array}{l}\text { Data are mean } \pm \mathrm{SD} \text {. } \\
\mathrm{HME}=\text { hat-and-moisture exchanger }\end{array}$} \\
\hline
\end{tabular}

with the Mann-Whitney test. $P<.05$ was considered to be statistically significant.

\section{Results}

Tables 1 and 2 show the percentage of nominal dose (mean $\pm \mathrm{SD}$ ) delivered distal to the trachea, using a heated humidifier, unheated humidifier, HME, and room air. Delivery efficiency of the jet nebulizer was significantly less than that of the mesh nebulizer using a heated humidifier, unheated humidifier, HME, and room air with both active exhaled humidity $(P=.043, P=.043, P=.043$, and $P=.043$, respectively) and passive exhaled humidity $(P=.02, P=-.02, P=.043$, and $P=.043$, respectively). Aerosol delivery with each nebulizer was greatest on room air and lowest with a heated humidifier with and without exhaled humidity. All comparisons of the heated humidifier, unheated humidifier, HME, and room air on aerosol delivery using the jet nebulizer with active exhaled humidity were statistically significant $(P<.05)$. With active exhaled humidity, deposited doses with the mesh nebulizer between HME and room air $(P=.30)$ were 
similar. Aerosol deliveries obtained by jet and mesh nebulizers without active exhaled humidity were statistically significant with all humidification systems tested in this study $(P<.05)$. No difference was found between HME and room air on drug deposition using jet and mesh nebulizers without exhaled humidity $(P=.47$ and $P=.35$, respectively).

Aerosol deposition with each nebulizer was lowest with the heated humidifier. The difference in drug delivery efficiency between the 2 aerosol generators was less with both the heated humidifier and unheated humidifier than with HME and room air.

Aerosol delivery with the unheated humidifier was greater than with the heated humidifier with both the jet and mesh nebulizers. Differences between active and passive humidity were greater with the jet nebulizer. Aerosol deposition using the jet nebulizer without active humidification probably overestimates the delivery of aerosol. Using the HME with passive exhaled humidification, drug delivery was greater with both the jet nebulizer (trend, $P=.08)$ and mesh nebulizer $(P=.043)$, showing no difference in delivery with room air. However, with active exhaled humidity, drug delivery was greater with room air than with the HME with both the jet nebulizer and mesh nebulizer. This difference would account for the losses of exhaled aerosol in HME versus the open reservoir tube with room air. Further study is required to understand why the difference between active and passive exhaled delivery is greater with the jet nebulizer than with the mesh nebulizer and why differences with the mesh nebulizer were greater with the HME/room air than with the heated humidifier/unheated humidifier.

\section{Discussion}

This is the first study to examine the effects of commonly used nebulizer/humidification combinations and exhaled air on aerosol deposition in a simulated lung model of tracheostomy.

We found substantial differences in drug delivered distal to the trachea between the types of nebulizer, the 4 conditions of humidification, and the 2 models used. The jet nebulizer was less efficient than the mesh nebulizer in all conditions tested in this study. This is due in part to the difference in residual drug remaining in the nebulizer at the end of aerosol administration. Jet nebulizers have a residual drug volume at end of treatment of approximately $0.8-1.4 \mathrm{~mL}$, reducing the amount of aerosol emitted to $1.6-2.2 \mathrm{~mL}$ of drug. The mesh nebulizer has $0.1 \mathrm{~mL}$ remaining in the reservoir at the end of aerosol production, so $2.9 \mathrm{~mL}$ is emitted as aerosol. Consequently, we would expect between 32 and $81 \%$ more drug to be emitted with the vibrating mesh nebulizer than with the jet nebulizer. This would be consistent with the differences in aerosol delivery between the jet nebulizer and the vibrating mesh nebulizer with both the unheated and heated humidifier. However, the relative efficiency of the 2 nebulizers was considerably different with HME and room air.

Since the emitted dose of the jet nebulizer and vibrating mesh nebulizer would be consistent across all conditions, the key difference between inhaled dose with the unheated and heated humidifiers versus HME and room air conditions is the $40 \mathrm{~L} / \mathrm{min}$ of gas flow from the humidification devices in which the emitted aerosol was carried. At 40 $\mathrm{L} / \mathrm{min}$, aerosol is diluted in $668 \mathrm{~mL} / \mathrm{s}$ of gas. With a tidal volume of $400 \mathrm{~mL}$ with a 1-s inspiratory time, the total flow of the carrier gas exceeds the model's inspiratory flow by $40 \%$. Consequently, inspiration only includes $60 \%$ of the aerosol-containing gas flowing to the interface during inspiration, with two thirds of the aerosolcontaining gas flow flushed through the interface between inspirations.

Ari et al, ${ }^{10}$ studying the impact of total flow on aerosol delivery with high-flow nasal cannula reported reductions of inhaled aerosol dose as total flow increased in infant, toddler, and adult models. The higher the total flow passing through the aerosol, the lower the inhaled dose. The authors suggested that the more the total flow exceeds the inspiratory flow of the model, the less aerosol is available to be inhaled. ${ }^{10}$ This was consistent with the findings of Perry et al, ${ }^{11}$ using a different humidification system for administration of high-flow nasal cannula, who reported a decrease in inhaled dose as total flow delivered to the subject increased.

In contrast, with HME and room air, aerosol was inhaled based on the inspiratory pattern of the model drawing gas from the ambient environment, without dilution in the $40 \mathrm{~L} / \mathrm{min}$ flow with the heated humidifier and unheated humidifier. This reduction in total gas flow resulted in a $50-200 \%$ increase in aerosol delivery with the jet nebulizer and $>400 \%$ with the mesh nebulizer. Because the residual drug of the individual nebulizers would be unchanged, the greater difference is probably due to the 10$\mathrm{L} / \mathrm{min}$ flow used to operate the jet nebulizer. Equivalent to $167 \mathrm{~L} / \mathrm{s}$ with the $1: 2$ inspiratory-expiratory ratio, $333 \mathrm{~mL}$ of gas flushes through the circuit $(<150 \mathrm{~mL})$ between end inspiration and the beginning of the next breath and is lost to the filtering effect of the HME or of the ambient air with room air. In contrast, the mesh nebulizer requires no gas flow to operate, and emitted aerosol collects as a bolus in the setup between end expiration and the beginning of inspiration.

The addition of active exhaled humidity to the model resulted in a reduction in drug delivery compared with non-heated/humidified exhalation of the passive humidity in some cases, with the greatest reduction up to $44 \%$ with the jet nebulizer. This difference suggests that passive unheated exhalation may overestimate delivery compared 
with active humidification of exhalation by $3-44 \%$, depending on the specific conditions tested.

A number of in vitro studies evaluating aerosol delivery via artificial airways have reported a reduction in drug delivered distal to the airway when aerosol is delivered with heated humidification rather than ambient conditions. ${ }^{12,13}$ This observation is so common that there is a widespread assumption that the heated humidity reduces delivery of inhaled drugs to the lung by $40 \%$ or more. However, a common feature of the in vitro models used in these studies has been that exhaled gas returning from the lung has not been actively humidified to simulate typical exhaled temperatures and absolute humidity. It is possible that exhaled humidity reduces inhaled dose by a mechanism similar to that attributed to aerosol administered with heated humidity. As Lange and Finlay ${ }^{14}$ have described, the effect on hygroscopic growth of particles is a function of absolute humidity, and the process can occur quite rapidly as the aerosol comes into contract with the heated/humidified gas, either in the ventilator circuit or as the aerosol enters into to the artificial airway.

During administration with the heated humidifier, the delivered drug from the jet nebulizer was $44 \%$ less with active exhaled humidity than the passive exhaled nonheated humidity in the more standard model. Only with inhalation of ambient room air did we find no difference in delivery with the jet nebulizer between active and passive humidity models. In contrast, the mesh nebulizer demonstrated only $1.6 \%$ reduction with the heated humidifier and $3 \%$ with the unheated humidifier but a greater reduction with HME (14\%) and room air (11\%). Our findings suggest that active exhaled humidity may more closely simulate patient airway interactions and that with some aerosol generators, data derived from aerosol delivery from the commonly used dry exhaled circuit may overestimate drug dose delivered. Reports from previous models that show greater deposition with dry conditions versus heated humidified conditions may be due in part to failure of the models to simulate exhaled heat and humidity. It should be noted that the deliveries of aerosol with HME and room air were consistent with levels of aerosol delivery reported by Ari et $\mathrm{al}^{12}$ with a jet nebulizer and a mesh nebulizer in a heated ventilator circuit.

In this study, we investigated the effect of heated humidified exhaled air on aerosol deposition delivered distal to the lung by using a heated humidifier that was placed between the aerosol collection filter and the breathing simulator to simulate heated and humidified exhaled air. Further adaptation to the active model may include insulating and heating the airways to better simulate exhaled humidity as it occurs in vivo. Where we found some conditions in which passive humidity appears to overestimate delivery compared with active humidity, the results were inconsistent between conditions. Therefore, further research in this area will be required to understand the value of exhaled active humidity in these models.

Active exhaled humidity reduced aerosol drug delivery distal to the airways used in this lung model. Lin et al ${ }^{15}$ reported that aerosolized medication delivered with pressurized metered-dose inhalers in a ventilator circuit was similar to levels achieved with a dry ventilator circuit for the first hours after turning on the heated humidifier. They also observed that turning off the humidifier for $20 \mathrm{~min}$ before administration of aerosol did not improve aerosol drug delivery from the heated/humidified levels. According to Lin et al, ${ }^{15}$ the formation and presence of condensate play an important role in achieving the level of humidity associated with decreased aerosol delivery during mechanical ventilation. We saw considerable condensate that formed in the airway and circuit used with the lung model of this study. This condensate may have an effect on humidification similar to that reported by Lin et al. ${ }^{15}$

\section{Clinical Implications}

Although using aerosol and humidification therapy is a widespread practice in critically ill patients suffering from acute or chronic respiratory distress, the efficiency of aerosol and humidification devices in the treatment of patients with tracheostomy is lacking. Therefore, this study helps to fill the gaps in the literature and support clinicians in making informed decisions about which humidification and aerosol device to choose in patients with a tracheostomy. The findings of this bench study determine the most efficient nebulizer and humidification device to use in critically ill patients and inform clinicians as to the relative efficiency of the systems they are using. Such information will improve clinical practice, since it will lead to greater pulmonary deposition of aerosolized medication and possible greater clinical benefit in spontaneously breathing patients with a tracheostomy.

\section{Future Research}

The present study has the merit of being the first to compare different nebulizer/humidifier combinations for aerosol drug delivery to a simulated spontaneously breathing lung model with tracheostomy with or without exhaled humidity. This study also highlights the need for further research with animal models that show a difference in deposition with wet and dry circuits. Clinical studies should indeed be performed to assess the effects of different aerosol devices and humidifiers on aerosol drug delivery to patients with pulmonary diseases.

\section{Conclusions}

The results of this study demonstrate that aerosol drug delivery with each nebulizer was lowest with the 
heated humidifier and highest with the HME. Whereas the jet nebulizer was less efficient than the mesh nebulizer in all conditions tested in this study, exhaled humidity caused a decrease in aerosol deposition compared with nonheated/humidified exhalation. Further in vitro clinical studies are warranted.

\section{REFERENCES}

1. Dhand R. Special problems in aerosol delivery: artificial airways. Respir Care 2000;45(6):636-645.

2. Dhand R, Guntur VP. How best to deliver aerosol medications to mechanically ventilated patients. Clin Chest Med. 2008;29(2):277-296, vi.

3. Dhand R, Mercier E. Effective inhaled drug administration to mechanically ventilated patients. Expert Opin Drug Deliv 2007;4(1):47-61.

4. Berlinski A. Nebulized albuterol delivery in a model of spontaneously breathing children with tracheostomy. Respir Care 2013;58(12): 2076-2086.

5. Berlinski A, Chavez A. Albuterol delivery via metered dose inhaler in a spontaneously breathing pediatric tracheostomy model. Pediatr Pulmonol 2013;48(10):1026-1034.

6. Pitance L, Vecellio L, Delval G, Reychler G, Reychler H, Liistro G. Aerosol delivery through tracheostomy tubes: an in vitro study. J Aerosol Med Pulm Drug Deliv 2013;26(2):76-83.

7. Ari A, Fink JB, Dhand R. Inhalation therapy in patients receiving mechanical ventilation: an update. J Aerosol Med Pulm Drug Deliv 2012;25(6):319-332.
8. Ari A. Aerosol drug delivery in critical pulmonary care. Respir Care. 2015;60(6):858-874; discussion 874-879.

9. Ari A, Harwood RJ, Sheard MM, Fink JB. An in vitro evaluation of aerosol delivery through tracheostomy and endotracheal tubes using different interfaces. Respir Care 2012;57(7):1066-1070.

10. Ari A, Harwood R, Sheard M, Dailey P, Fink JB. In vitro comparison of heliox and oxygen in aerosol delivery using pediatric high flow nasal cannula. Pediatr Pulmonol 2011;46(8):795-801.

11. Perry SA, Kesser KC, Geller DE, Selhorst DM, Rendle JK, Hertzog $\mathrm{JH}$. Influences of cannula size and flow rate on aerosol drug delivery through the Vapotherm humidified high-flow nasal cannula system. Pediatr Crit Care Med 2013;14(5):e250-e256.

12. Ari A, Areabi H, Fink JB. Evaluation of position of aerosol device in two different ventilator circuits during mechanical ventilation. Respir Care 2010;55(7):837-844.

13. Ari A, Telli O, Harwood R, Sheard M, Fink JB. Influence of nebulizer type, position and bias flow on aerosol drug delivery in simulated pediatric and adult lung models during mechanical ventilation. Respiratory Care 2010;55(7):845-851.

14. Lange CF, Finlay WH. Overcoming the adverse effect of humidity in aerosol delivery via pressurized metered-dose inhalers during mechanical ventilation. Am J Respir Crit Care Med 2000;161(5):16141618.

15. Lin HL, Fink JB, Zhou Y, Cheng YS. Influence of moisture accumulation in inline spacer on delivery of aerosol using metered-dose inhaler during mechanical ventilation. Respir Care 2009;54(10): 1336-1341.

This article is approved for Continuing Respiratory Care Education credit. For information and to obtain your CRCE

(free to AARC members) visit

www.rcjournal.com

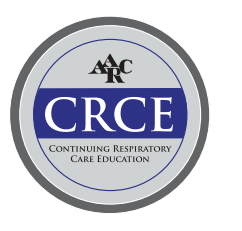

